\title{
Quantum-chemical modeling of the tautomeric equilibria of modified anionic nucleic acid bases
}

\author{
Mati Karelson and Andre Lomaka \\ Department of Chemistry, University of Tartu, Jakobi Street 2, 51014 Tartu, Estonia \\ E-mail:mati@chem.ut.ee
}

\section{Dedicated to Professor Kalevi Pihlaja on the occasion of his $60^{\text {th }}$ birthday}

(received 15 Jan 01; accepted 01 Jan 99; published on the web 18 Apr 02)

\begin{abstract}
The results of semiempirical quantum chemical calculations performed on the tautomeric forms of four modified anionic nucleic acid bases, i.e. the anions of the 1-methyl-5-hydroxyuracil, 1methyl-5-hydroxycytosine, 9-methyl-8-hydroxyadenine, and 9-methyl-8-hydroxyguanine, allow prediction of the mutagenically most active forms of these compounds. Preliminary calculations on base pairs between modified and normal bases indicate strong bonding to the most stable anionic tautomers of modified bases.
\end{abstract}

Keywords: Quantum-chemical modeling, tautomeric equilibria, nucleic acid bases

\section{Introduction}

It has been shown by us that the quantum chemical self-consistent reaction field (SCRF) method, in combination with AM1 (Austin Model 1) ${ }^{1}$ and PM3 (Parametric Model 3) ${ }^{2}$ semiempirical parameterization, gives confident predictions of the tautomeric equilibrium constants of different classes of heterocyclic compounds in aqueous solutions..$^{3-7}$ Other investigators using different levels of quantum theory ${ }^{8-10}$ have later confirmed the applicability of the SCRF method for the description of tautomeric equilibria in solutions. It has been also demonstrated that the relative stability of nucleic acid pyrimidine and purine bases and their 1-methyl analogues in solutions is correctly predicted using the AM1 and PM3 SCRF method. ${ }^{7}$ This has encouraged us to use the same approach for prediction of the tautomeric constitution of chemically modified nucleic acid bases in aqueous solutions. It has been known for some time that the 8-hydroxy- or 8-oxo-substituted purines exhibit substantial mutagenic activity. ${ }^{11-14}$ The 5-hydroxyuracil and, in particular, 5-hydroxycytosine are predicted to be some of the most efficient mutagenic agents. ${ }^{15,16}$ It has been also suggested that the active form would be the anion of the modified bases. Therefore, in order to study the possible mutagenic mechanism of these compounds, it would be important to estimate their tautomeric constitution in different media, 
especially in aqueous solutions. In the present paper, we report the results of the semiempirical quantum-chemical modeling of the tautomers of anions of four modified nucleic acid bases, i.e. the anions of the 1-methyl-5-hydroxyuracil (1), 1-methyl-5-hydroxycytosine (2), 9-methyl-8hydroxyadenine (3), and 9-methyl-8-hydroxyguanine (4) (Scheme 1). In addition, the structure and energetics of mixed normal base - modified base pairs was investigated quantum-chemically.

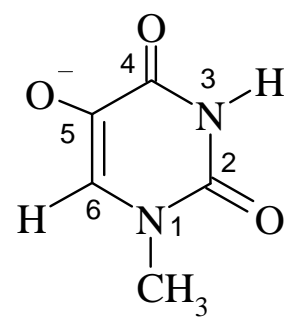

1

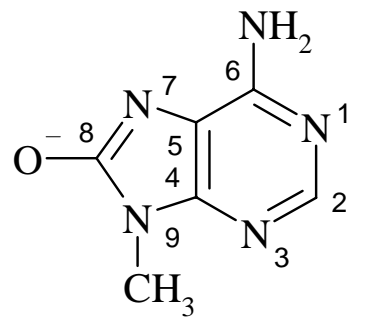

3

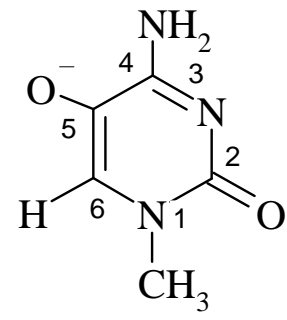

2

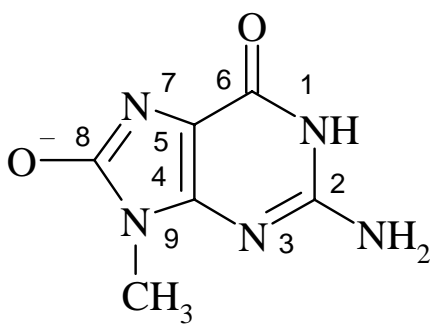

4

Scheme 1. The anions of modified nucleic acid bases.

The calculations were carried out using the AM1 and PM3 semiempirical methods. The comparative calculations of the anion of the 1-methyl-5-hydroxycytosine were made using the $a b$ initio SCF and DFT methods.

\section{Method}

The self-consistent reaction field (SCRF) method proceeds from the classical Kirkwood-Onsager theory ${ }^{17}$ of the electrostatic solute-solvent interactions in condensed dielectric media. The quantum mechanical extension of this theory has been described elsewhere ${ }^{18-20}$ and therefore we will give only its essentials here. According to Kirkwood and Onsager, the solvent is described as a polarizable dielectric continuum, characterized by its static dielectric constant, $\varepsilon$. The solute molecule is represented by $\mathrm{M}$ point charges (ei), situated at fixed points (ri) inside of sphere of radius $a_{0}$. By solving the appropriate electrostatic equations inside and outside the sphere and applying proper boundary conditions, one can find the potential at any point inside the cavity and the total electrostatic energy due to the molecular charge distribution interaction with the polarizable medium. In the quantum chemical application of this theory, this interaction energy is represented by the additional terms in the molecular Hamiltonian, which correspond nuclear-nuclear, nuclear-electronic and 
electron-electron contributions. ${ }^{20,21}$ For electroneutral dipolar solute molecules, the electronic Schrödinger equation to be solved using the self-consistent field method has the following form:

$$
\left(\hat{\mathbf{H}}_{\mathrm{o}}+\hat{\mathbf{V}}\right) \Psi=E_{e l} \Psi
$$

where $\hat{\mathbf{H}}_{\mathrm{o}}$ is the total electronic Hamiltonian for the isolated molecule, $\Psi$ denotes the electronic wavefunction and is the solvent reaction field perturbation operator. In the last equation, $\hat{\mu}_{\text {denotes the }}$ dipole moment operator and $\langle\varphi|\hat{\mu}| \varphi\rangle$ - the expectation value of total dipole moment of the solute molecule.

$$
\hat{\mathbf{V}}=\frac{2(\varepsilon-1)}{(2 \varepsilon+1) a_{o}^{3}}\langle\varphi|\hat{\mu}| \varphi\rangle \hat{\mu}
$$

In the case of ionic compounds with the ionic charge $Q$, the classical Born term has to be added to the quantum-chemical energy, $E_{Q M}$, to obtain the total energy of the molecule in solution:

$$
E_{\text {tot }}(\text { ion })=E_{Q M}+\frac{1-\varepsilon}{\varepsilon a_{0}} Q^{2}
$$

The use of the SCRF model in quantum-chemical theory requires that the shape and volume of the solute molecule must be defined uniquely for any set of compounds. A number of approaches to calculate these characteristics are known, but no non-empirical methods for their estimation have been developed. However, from the results of model calculations it may be concluded that the simple model assuming a spherical or an ellipsoidal shape of the cavity for the solute molecule is probably satisfactory for comparatively small and rigid molecules. ${ }^{21}$ Therefore, this method was selected in the present calculations. The calculations of base pairs were performed using the multi-cavity SCRF method (MCa SCRF) ${ }^{22}$. In all cases, the full optimization of the molecular structure was carried out.

\section{Results and Discussion}

AM1 and PM3 self-consistent field (SCF) and SCRF calculations were carried out for individual tautomeric forms of the anions of 1-methyl-5-hydroxyuracil (1), 1-methyl-5-hydroxycytosine (2), 9methyl-8-hydroxyadenine (3), and 9-methyl-8-hydroxyguanine (4). The notations of tautomeric forms are defined on Schemes 2-5. 
<smiles>Cn1cc([O-])c(=O)[nH]c1=O</smiles>

1a<smiles>Cn1cc(O)c([O-])nc1=O</smiles>

$1 b$<smiles>Cn1cc([O-])c(=O)nc1O</smiles>

1c<smiles>Cn1cc([O-])c(O)nc1=O</smiles>

1d

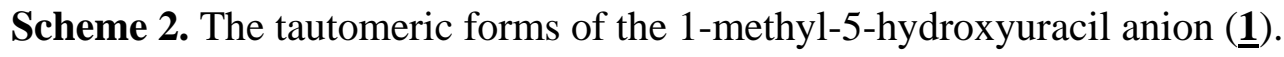<smiles>Cn1cc([O-])c(N)nc1=O</smiles>

2a<smiles>Cn1cc(O)c(=N)nc1[O-]</smiles>

2b<smiles>Cn1cc([O-])c(=N)[nH]c1=O</smiles>

2c<smiles>Cn1cc([O-])c(=N)nc1O</smiles>

2d

Scheme 3. The tautomeric forms of the 1-methyl-5-hydroxycytosine (2) anion.<smiles>Cn1c([O-])nc2c(N)ncnc21</smiles>

3a<smiles>Cn1c([O-])nc2c(=N)[nH]cnc21</smiles>

$3 b$<smiles>Cn1c([O-])nc2c(=N)nc[nH]c21</smiles>

3c

Scheme 4. The tautomeric forms of the 9-methyl-8-hydroxyadenine (므) anion. 
<smiles>Cn1c([O-])nc2c(=O)[nH]c(N)nc21</smiles>

4a<smiles>Cn1c(O)nc2c([O-])nc(N)nc21</smiles><smiles>Cn1c(=O)[nH]c2c([O-])nc(N)nc21</smiles>

4b<smiles>Cn1c([O-])nc2c(=O)nc(N)[nH]c21</smiles>

4c

4d

Scheme 5. The tautomeric forms of the 9-methyl-8-hydroxyguanine (3) anion.

All tautomeric forms were studied in two media, the first of which corresponds to the isolated molecule in the gas phase $(\varepsilon=1)$ and the second to a condensed polarizable medium with the dielectric constant of water at the $20^{\circ} \mathrm{C}(\varepsilon=80)$. The following cavity radii, obtained from the estimated mass densities of compounds, were used throughout the calculations: $3.598 \AA$ for $1,3.887 \AA$ for 2, $4.246 \AA$ for 3, and $4.285 \AA$ for 4 . The mass densities of all compounds were taken as $d=1$ $\mathrm{g} / \mathrm{cm}^{3}$, based on the densities of similar liquid heterocyclic compounds (pyridine, pyrimidine etc.). The calculated heats of formation of different tautomeric species of compounds $\mathbf{1}-\mathbf{4}$, the corresponding tautomeric equilibrium energies and tautomeric equilibrium constants are given in Tables 1 - 4, respectively. The $\mathrm{pK}_{\mathrm{T}}$ values were estimated proceeding from the assumption that the entropy change during the tautomerization process is small. Accordingly, where $\Delta \mathrm{GT}_{\mathrm{T}}$ is the free energy of the tautomeric equilibrium and $\delta \Delta \mathrm{H}$ is the difference between the calculated heats of formation of the two tautomeric species participating in this equilibrium.

$$
\mathrm{pK}_{\mathrm{T}}=\frac{\Delta \mathrm{G}_{\mathrm{T}}}{2.303 \mathrm{RT}} \approx \frac{\delta \Delta \mathrm{H}}{2.303 \mathrm{RT}}
$$

The results of calculations indicate that the most stable tautomer of the anion of 1-methyl-5hydroxyuracil in the solution is the form with the intact OH-group at the 5-position (1b). With the small exception for the PM3 calculation in the gas phase, this tautomer seems also to be the most stable form in low dielectric constant media (gas phase). The calculations using quantum theory at the 
$a b$ initio level of theory confirm these results. Thus, the HF/6-31G(d) theory in combination with the above-described Onsager solvation mode ${ }^{23}$ predicts the tautomer $\mathbf{1 b}$ to be by $3.22 \mathrm{kcal} / \mathrm{mol}$ more stable in the solution as compared to the next most stable tautomer 1a. The use of density functional theory at BLYP/6-31+G(d) level ${ }^{23}$ gives a similar result $\left(\Delta \mathrm{pK}_{\mathrm{T}}=0.9\right) \cdot{ }^{24}$ Consequently, because of the lack of the hydrogen atom at N3 position, the normal pairing of the 1-methyl-5-hydroxyuracil anion tautomer $\mathbf{1 b}$ with adenine is incapacitated. However, this tautomeric form of 1-methyl-5hydroxyuracil anion (1b) produces a strongly bonded complex with guanine as the reverse WatsonCrick pair (Scheme 6).

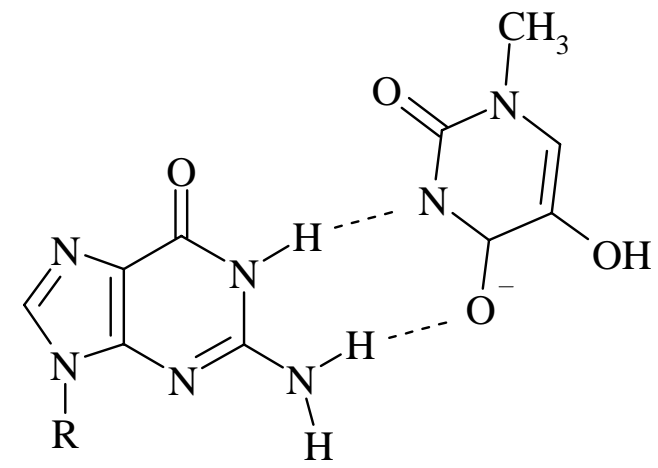

Scheme 6. The reverse Watson-Crick pair between guanine and 1-methyl-5-hydroxyuracil ( $\underline{\mathbf{1 b}})$.

Because of the substantial negative charge on the C4 carbonyl (close to the oxy-anion) of the 1methyl-5-hydroxyuracil anion $\mathbf{1 b}$, this pair will be strongly bonded and may cause the termination of the DNA replication. The AM1 and PM3 SCF calculations reveal that the reverse Watson-Crick pair between guanine and 1-methyl-5-hydroxyuracil anion is by $2.05 \mathrm{kcal} / \mathrm{mol}$ (AM1) to $4.17 \mathrm{kcal} / \mathrm{mol}$ (PM3) more stable than the normal guanine-cytosine pair.

In the case of the 1-methyl-5-hydroxycytosine anion, both AM1 and PM3 SCRF methods predict the structure $\mathbf{2} \mathbf{b}$ as the most stable tautomeric form in the solution. This $\mathrm{N}-\mathrm{H}$ form of the anion has substantial negative charge on the C2 carbonyl oxygen atom. In result, the respective pair with the guanine (Scheme 7) is significantly more strongly bonded than the normal guanine-cytosine pair.

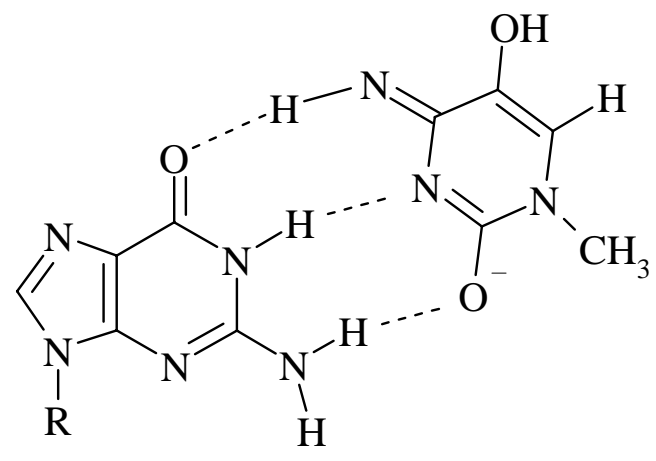

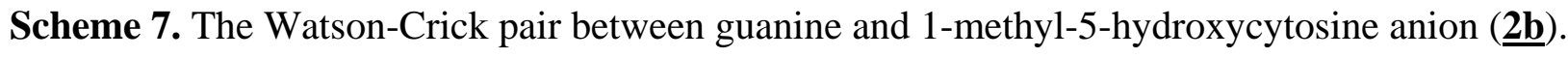


The AM1 SCF calculations predict that the abnormal guanine - $\mathbf{2 b}$ pair is by $5.42 \mathrm{kcal} / \mathrm{mol}$ more stable than the normal guanine - cytosine Watson-Crick pair. The respective calculated difference using PM3 parameterization is even larger, i.e. $10.21 \mathrm{kcal} / \mathrm{mol}$. Consequently, such strong bonding may substantially affect the normal DNA replication process and lead to the mutations or even cell termination.

In the case of anions of 9-methyl-8-hydroxyadenine and 9-methyl-8-hydroxyguanine, the most stable tautomeric forms, both in the gas phase and in the solution, are the ionized 8-hydroxyl forms 3a and 4a, respectively. In both cases, the normal bonding with uracil and adenine is only slightly affected. However, our preliminary calculations indicate that the most stable tautomers in the solution of the neutral 9-methyl-8-hydroxyadenine and 9-methyl-8-hydroxyguanine are the zwitterionic forms 5 and $\mathbf{6}$, respectively, presented on Scheme 8.<smiles>Cn1c([O-])nc2c([NH3+])ncnc21</smiles>

5<smiles>Cn1c([O-])nc2c(=O)[nH]c([NH3+])nc21</smiles>

6

Scheme 8. The predicted most stable tautomeric forms of the neutral 9-methyl-8-hydroxyadenine and 9-methyl-8-hydroxyguanine in the solution.

According to the AM1 SCRF calculations, the form 5 is by $13.50 \mathrm{kcal} / \mathrm{mol}$ more stable as the neutral 8-hydroxy-4-amino-form of the 9-methyl-8-hydroxyadenine. The tautomeric form 6 is predicted by the same method to be by $10.33 \mathrm{kcal} / \mathrm{mol}$ more stable as the neutral 8-hydroxy-2-aminoform of the 9-methyl-8-hydroxyguanine. The participation of charged $\mathrm{NH}_{3}^{+}$-group in the pair hydrogen bonding of $\mathbf{5}$ and $\mathbf{6}$ with uracil and cytosine, respectively, should significantly increase the stability of the respective base pairs (Scheme 9). 


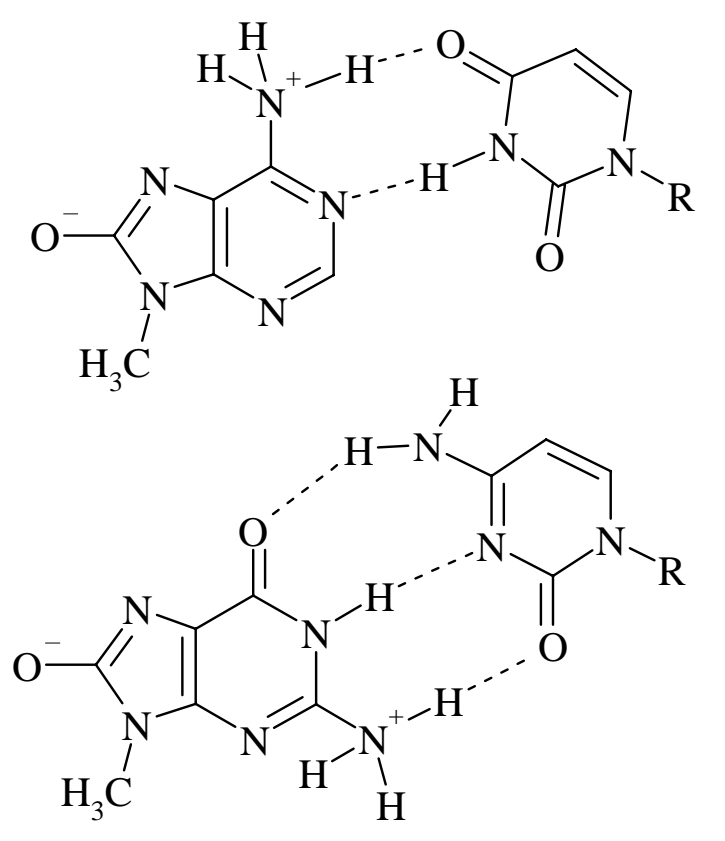

Scheme 9. The predicted most stable nucleic acid base pairs between the 9-methyl-8-hydroxyadenine and 9-methyl-8-hydroxyguanine zwitterions and uracil and cytosine, respectively.

Indeed, the results obtained using the AM1 SCF method confirm this hypothesis. The 9-methyl-8hydroxyadenine zwitterionic tautomer 5 pair with uracil was estimated to be by $5.16 \mathrm{kcal} / \mathrm{mol}$ (AM1 MCa SCRF) to $8.41 \mathrm{kcal} / \mathrm{mol}$ (PM3 MCa SCRF) more stable than the normal adenine-uracil pair. The 9-methyl-8-hydroxyguanine zwitterionic tautomer 6 pair with cytosine was predicted to be more stable than the normal guanine-cytosine pair by $7.22 \mathrm{kcal} / \mathrm{mol}$ (AM1 MCa SCRF) to $8.17 \mathrm{kcal} / \mathrm{mol}$ (PM3 MCa SCRF).

\section{Conclusions}

The results of the semiempirical quantum-chemical modeling of the tautomeric constitution of oxidatively modified DNA bases and their pairing with normal nucleic acid bases are indicative regarding the possible mutagenic mechanism of these compounds. The most stable tautomeric forms of the 9-methyl-8-hydroxyadenine and 9-methyl-8-hydroxyguanine in solution are zwitterionic and give abnormally strong bonding with the respective pyrimidine bases. As a result, the strongly bonded DNA chains may affect the process of replication with the subsequent mutations or cell termination. An analogous mechanism is expected in the case of the 1-methyl-5-hydroxycytosine anion (2b) that should be strongly bonded with guanine. In the case of 1-methyl-5-hydroxyuracil anion, the possible mechanism of the mutagenic activity may be related to the strong reverse Watson-Crick bonding of this compound with the wrong purine base (guanine). 
Table 1. The AM1 and PM3 SCF $(\varepsilon=1)$ and SCRF $(\varepsilon=80)$ calculated heats of formation $\Delta \mathrm{H}_{\mathrm{f}}^{0}$, and the relative tautomeric equilibrium constants $\Delta \mathrm{pKT}$ of the different tautomeric species of the anion 1methyl-5-hydroxyuracil (1). The definition of tautomeric forms is given on Scheme 2

\begin{tabular}{ccccr}
\hline Tautomer & Method & $\varepsilon$ & $\Delta \mathrm{H}_{\mathrm{f}}^{0}(\mathrm{kcal} / \mathrm{mol})$ & $\Delta \mathrm{pK}_{\mathrm{T}}$ \\
\hline 1a & AM1 & 1 & -117.70 & 0.25 \\
& & 80 & -170.04 & 2.37 \\
& PM3 & 1 & -144.06 & $(0)$ \\
1b & & 80 & -195.07 & 4.40 \\
& AM1 & 1 & -118.05 & $(0)$ \\
& & 80 & -173.31 & $(0)$ \\
& PM3 & 1 & -143.84 & 0.16 \\
1c & & 80 & -201.13 & $(0)$ \\
& AM1 & 1 & -94.99 & 16.72 \\
& & 80 & -160.90 & 9.00 \\
& PM3 & 1 & -126.54 & 12.71 \\
1d & & 80 & -191.74 & 6.81 \\
& AM1 & 1 & -108.11 & 7.21 \\
& & 80 & -155.49 & 12.92 \\
& PM3 & 1 & -136.67 & 5.36 \\
& & 80 & -183.60 & 12.71 \\
\hline
\end{tabular}

Table 2. The AM1 and PM3 SCF $(\varepsilon=1)$ and SCRF $(\varepsilon=80)$ calculated heats of formation $\Delta \mathrm{H}_{\mathrm{f}}^{0}$, and the relative tautomeric equilibrium constants $\Delta \mathrm{pKT}$ of the different tautomeric species of the anion 1-methyl-5-hydroxycytosine (2). The definition of tautomeric forms is given on Scheme 3

\begin{tabular}{ccccr}
\hline Tautomer & Method & $\varepsilon$ & $\Delta \mathrm{H}_{\mathrm{f}}^{0}(\mathrm{kcal} / \mathrm{mol})$ & $\Delta \mathrm{pK}_{\mathrm{T}}$ \\
\hline 2a & AM1 & 1 & -62.13 & $(0)$ \\
& & 80 & -104.41 & 1.02 \\
& PM3 & 1 & -88.55 & 0.46 \\
\multirow{2}{*}{ 2b } & & 80 & -131.53 & 3.88 \\
& AM1 & 1 & -58.83 & 2.39 \\
& & 80 & -105.82 & $(0)$ \\
& PM3 & 1 & -87.87 & 0.96 \\
2c & & 80 & -136.19 & $(0)$ \\
& AM1 & 1 & -60.87 & 0.91 \\
& & 80 & -105.38 & 0.32 \\
& PM3 & 1 & -89.19 & $(0)$ \\
2d & & 80 & -133.53 & 1.93 \\
& & 1 & -40.80 & 15.47 \\
\hline
\end{tabular}


Table 2. Continued

\begin{tabular}{rcrr}
\hline & 80 & -92.93 & 9.35 \\
\multirow{2}{*}{ РM3 } & 1 & -72.06 & 12.42 \\
& 80 & -123.55 & 9.17 \\
\hline
\end{tabular}

Table 3. The AM1 and PM3 SCF $(\varepsilon=1)$ and SCRF $(\varepsilon=80)$ calculated heats of formation $\Delta \mathrm{H}_{\mathrm{f}}^{0}$, and the relative tautomeric equilibrium constants $\triangle \mathrm{pKT}$ of the different tautomeric species of the anion 9-methyl-8-hydroxyadenine (3). The definition of tautomeric forms is given on Scheme 4

\begin{tabular}{ccccr}
\hline Tautomer & Method & $\varepsilon$ & $\Delta \mathrm{H}_{\mathrm{f}}^{0}(\mathrm{kcal} / \mathrm{mol})$ & $\Delta \mathrm{pK}_{\mathrm{T}}$ \\
\hline 3a & AM1 & 1 & 11.97 & $(0)$ \\
& & 80 & -26.96 & $(0)$ \\
& PM3 & 1 & -17.38 & $(0)$ \\
\multirow{3}{*}{ 3b } & & 80 & -56.20 & $(0)$ \\
& AM1 & 1 & 28.18 & 11.76 \\
& & 80 & -13.98 & 9.42 \\
& PM3 & 1 & -1.61 & 11.44 \\
\multirow{3}{*}{ 3c } & & 80 & -42.19 & 10.61 \\
& AM1 & 1 & 30.42 & 13.38 \\
& & 80 & -14.09 & 9.33 \\
& PM3 & 1 & 3.05 & 10.16 \\
& & 80 & -38.19 & 13.06 \\
\hline
\end{tabular}

Table 4. The AM1 and PM3 SCF $(\varepsilon=1)$ and SCRF $(\varepsilon=80)$ calculated heats of formation $\Delta \mathrm{H}_{\mathrm{f}}^{0}$, and the relative tautomeric equilibrium constants $\triangle \mathrm{pKT}$ of the different tautomeric species of the anion 9-methyl-8-hydroxyguanine (4). The definition of tautomeric forms is given on Scheme 5

\begin{tabular}{ccccr}
\hline Tautomer & Method & $\varepsilon$ & $\Delta \mathrm{H}_{\mathrm{f}}^{0}(\mathrm{kcal} / \mathrm{mol})$ & $\Delta \mathrm{pK}_{\mathrm{T}}$ \\
\hline 4a & AM1 & 1 & -28.78 & $(0)$ \\
& & 80 & -74.99 & $(0)$ \\
& PM3 & 1 & -64.28 & $(0)$ \\
4b & & 80 & -109.91 & $(0)$ \\
& AM1 & 1 & -3.52 & 18.32 \\
& & 80 & -42.92 & 23.26 \\
\multirow{4}{*}{ 4c } & PM3 & 1 & -49.96 & 10.39 \\
& & 80 & -89.05 & 14.71 \\
& AM1 & 1 & 2.12 & 22.41 \\
& & 80 & -39.18 & 25.97 \\
& PM3 & 1 & -39.02 & 18.32 \\
\hline
\end{tabular}


Table 4. Continued

\begin{tabular}{rccrr}
\hline \multirow{4}{*}{ 4d } & & 80 & -79.45 & 22.09 \\
& AM1 & 1 & -22.45 & 4.59 \\
& & 80 & -71.76 & 2.34 \\
& PM3 & 1 & -106.24 & 3.82 \\
& & 80 & -59.01 & 2.66 \\
\hline
\end{tabular}

\section{References}

1. Dewar, M. J. S.; Zoebisch. E. G.; Healy, E. F.; Stewart, J. J. P. J. Am. Chem. Soc. 1985, 107, 3902.

2. Stewart, J. J. P. J. Comput. Chem. 1989, 10, 209.

3. Karelson, M.; Katritzky, A. R.; Szafran M.; Zerner, M. C. J. Org. Chem. 1989, 54, 6030.

4. Karelson, M; Tamm, T.; Katritzky, A. R.; Cato, S. J; Zerner, M. C. Tetrahedron Comp. Methodol. 1989, 2, 295

5. Karelson, M.; Katritzky, A. R.; Szafran. M.; Zerner, M. C. J. Chem. Soc., Perkin Trans. 2 1990, 195.

6. Oksman, P.; Fajer, G.; Pihlaja, K.; Karelson, M. J. Am. Soc. Mass Spectrom. 1994, 5, 113.

7. Katritzky, A. R.; Karelson, M. J. Am. Chem. Soc. 1991, 113, 1561.

8. Parchment, O. G.; Hillier, I. H.; Green, D. V. S.; Burton, N. A.; Morley, J. O.; Schaefer, H. F. III J. Chem. Soc., Perkin Trans. 2 1992, 1681.

9. Woodcock, S.; Green, D. V. S.; Vincent, M. A.; Hillier, I. H.; Guest, M. F.; Sherwood, $\quad$ P. $\quad J$. Chem. Soc., Perkin Trans. 2 1992, 2151.

10. Gu, J. D.; Leszczynski, J. J. Phys. Chem. A 1999, 103, 577.

11. Maccubbin, A. E.; Ersing, N.; Budzinski, E. E.; Box, H. C.; Gurtoo, H. L. Cancer Biochem. Biophys. 1994, 14, 183.

12. Spencer, J. P.; Jenner, A.; Chimel, K.; Aruoma, O. I.; Cross, C. E.; Wu, R.; Halliwell, B. FEBS Lett. 1995, 374, 233.

13. Roldan-Arjona, T.; Wei, Y. F.; Carter, K. C.; Klungland, A.; Anselmino, C.; Wang, R. P.; Augustus, M.; Lindahl, T. Proc Natl Acad Sci USA 1997, 94, 8016.

14. Purmal, A. A.; Kow, Y. W.; Wallace, S. S. Nucl. Acids Res. 1994, 22, 72.

15. Wu Suen; Spiro, T. G.; Sowers, L. C.; Fresco, J. R. Proc Natl Acad Sci USA 1999, 96, 4500.

16. Böttcher, C. J. F.; Bordewijk, P. Theory of Electric Polarization; $2^{\text {nd }}$ Ed; Elsevier Co: Amsterdam, 1978; Vol. II.

17. Hylton, J.; Christoffersen, R. E.; Hall, G. G. Chem. Phys. Lett. 1974, 26, 501.

18. Tapia, O.; Goscinski, O. Mol. Phys. 1975, 29, 1653.

19. Karelson, M. Theoretical Treatment of Solvent Effects on Electronic and Vibrational Spectra of Compounds in Condensed Media In Handbook of Solvents, Wypych, G., Ed; ChemTec Publishing: Toronto, 2000; pp 607-647. 
20. Karelson, M. M.; Zerner, M. C. J. Phys. Chem. 1992, 96, 6949.

21. Karelson, M.; Tamm, T.; Zerner, M. C. J. Phys. Chem. 1993, 97, 11901.

22. Frisch, M. J.; Trucks, G. W.; Schlegel, H. B., Gill, P. M. W. Gaussian 94, Revision D.2;

23. Johnson, B. G.; Robb, M. A.; Cheeseman, J. R.; Keith, T.; Petersson, G. A.; Montgomery, J. A.; Raghavachari, K.; Al-Laham, M. A.; Zakrzewski, V. G.; Ortiz, J. V.; Foresman, J. B.; Cioslowski, J.; Stefanov, B. B.; Nanayakkara, A.; Challacombe, M.; Peng, C. Y.; Ayala, P. Y.; Chen, W.; Wong, M. W.; Andres, J. L.; Replogle, E. S.; Gomperts, R.; Martin, R. L.; Fox, D. J.; Binkley, J. S.; Defrees, D. J.; Baker, J.; Stewart, J. P.; Head-Gordon, M.; Gonzalez, C.; Pople, J. A.; Gaussian, Inc., Pittsburgh PA, 1995.

24. Karelson, M.; Katritzky A. R.; Fresco, J. Estimation of the Tautomeric Equilibria of Mutagenic Nucleic Acid Base Analogs by Quantum-Chemical Modeling, in preparation. 